\title{
REPRODUCTIVE ECOLOGY OF BIRDVILLE INDIGO, INDIGOFERA LINNAEI ALI. (FABACEAE)
}

\section{G. Lakshminarayana and A. J. Solomon Raju}

Journal of Institute of Science and Technology

Volume 22, Issue 1, July 2017

ISSN: 2469-9062 (print), 2467-9240 (e)

Editors:

Prof. Dr. Kumar Sapkota

Prof. Dr. Armila Rajbhandari

Assoc. Prof. Dr. Gopi Chandra Kaphle

JIST, 22 (1): 84-93 (2017)

Published by:

Institute of Science and Technology

Tribhuvan University

Kirtipur, Kathmandu, Nepal 


\title{
REPRODUCTIVE ECOLOGY OF BIRDVILLE INDIGO, INDIGOFERA LINNAEI ALI. (FABACEAE)
}

\author{
G. Lakshminarayana ${ }^{1}$ and A. J. Solomon Raju ${ }^{2, *}$ \\ ${ }^{1}$ Department of Environmental Sciences, Gayathri Vidya Parishad Degree College, M. V. P. Colony, \\ Visakhapatnam-530 017, India \\ ${ }^{2}$ Department of Environmental Sciences, Andhra University, Visakhapatnam, India \\ *Corresponding E-mail: solomonraju@gmail.com
}

\begin{abstract}
Indigofera linnaei, a low ground herb is an important species of herbaceous cover. It forms extensive mats of populations carpeting the soil. But, it is not known how it is able to increase its population size and spread into other areas. The knowledge of its reproductive ecology is important to understand its reproductive capabilities and evaluate its use in eco-restoration initiatives. The study aims to provide information on its reproductive ecology. I. linnaei flowers are papilionaceous, bisexual, monostylous, weakly protandrous, self-compatible, facultatively xenogamous and possess explosive pollination mechanism. High winds, high temperature and heavy rain trip the pollination mechanism and effect only selfing while bees and lycaenid butterflies trip pollination mechanism and affect both selfing and outcrossing. Thrips use the flower buds for breeding, emerge during anthesis and pollinate the flowers by feeding on pollen and nectar. The fruit is a pod which dehisces explosively to disperse seeds; long distance dispersal is facilitated by their irregular shape, oily nature, and carried away by wind and rain water. Therefore, ballistichory, anemochory and hydrochory are the functional modes of seed dispersal that enable the plant to invade and colonize especially open, sandy dry areas. The plant provides food for certain local insects and protects the soil cover with its clustered root system and spreading form of multi-stemmed branching pattern. Therefore, I. linnaei has the potential for use in the restoration of destroyed, degraded and damaged habitats.
\end{abstract}

Keywords: Indigofera linnaei, facultative xenogamy, explosive pollination mechanism, abiotic and biotic pollination, ballistichory, anemochory and hydrochory.

\section{INTRODUCTION}

The herb layer has structural and functional significance in both forest and non-forest ecosystems. Certain low ground herbs have the ability in retarding soil, water and nutrient erosion and these abilities vary with different weed species (Kumar et al., 1997). In this context, Gebrekirstos et al. (2006) stated that the herbaceous weeds are important in reforestation programs to initiate ground flora in order to pave the way for the successional communities. But, lack of knowledge on the biology and ecology of herbaceous weeds and their adaptation to environmental stress is a drawback to use them in the reforestation programs in order to counteract the effects of degraded sites where soil water is a major limiting factor in the growth, species composition and distribution of species. Collevatti et al. (1998) stated that the knowledge of invertebrates and their interactions with native plants should be included in designing restoration programs and in ecological resilience. In this context, the herbaceous species of Indigofera assume importance since they normally grow as minor or major invasive weeds. The knowledge of the reproductive ecology of these species is essential to use them for the restoration of degraded areas.

Wilson (1987) and Wilson \& Ross (2004) provided a general account on Indigofera genus. It is a large pantropical genus of Fabaceae with over 750 species mostly of shrubs and a few of small trees or annual or perennial herbs distributed in all arid zones of the tropical and sub-tropical regions of world. Majority of taxa occur in Africa with other centers of diversity in Arabia to South East Asia, Mexico to sub-tropical North and South America, Australia and Madagascar. Most species have flowers in shades of red, but there are a few white- 
and yellow-flowered species. The flowers are hermaphrodite, zygomorphic and possess conspicuously specialized explosive pollination mechanism. The fruit is a legume pod with seeds dispersed in an explosive manner. Indigofera species have not been studied for their reproductive ecology despite their importance in painting, medicinal and cosmetic purposes since ancient times. Therefore, the present study is contemplated to provide the information on floral morphology, biology, flowers visitors, pollination, fruiting ecology and seed dispersal of Indigofera linnaei. It is an important species of herbaceous cover and forms extensive mats of populations carpeting the soil. The knowledge of its reproductive ecology is important to understand its reproductive capabilities and evaluate its use in eco-restoration initiatives.

\section{MATERIALS AND METHODS}

The wild patches of Indigofera linnaei growing in Visakhapatnam and its surroundings $\left(17^{\circ} 42^{\prime} \mathrm{N}\right.$ Latitude and $82^{\circ} 18^{\prime}$ E Longitude) were used for the study. Field trips were conducted to record phenological aspects. Ten inflorescences which have not initiated flowering on five plants, each one situated $500 \mathrm{~m}$ apart were tagged in August and followed daily to record the duration of flowering, anthesis schedule and the timing of anther dehiscence. Twenty five fresh flowers were used to record the floral morphological details. Nectar could not be measured and analyzed due to its secretion in minute quantity which was further depleted by thrips during mature bud and flower life. Twenty mature, but un-dehisced anthers, two anthers each per flower/plant from ten plants were collected and examined for pollen output as per the protocol described in Dafni et al. (2005). The calculation of pollen output per flower and pollenovule ratio was done as per the formulas described in Cruden (1977). The fresh pollen grains were collected from virgin flowers after anther dehiscence from bagged inflorescences and placed in Petri dish in lab conditions. They were placed in cavity slides with $15 \%$ pure sucrose solution, placed cover slip on them. The percentage of pollen tubes formed from the pollen grains at hourly intervals was recorded. Ten flowers each from five individuals were used to test stigma receptivity. It was tested with hydrogen peroxide from mature bud stage to flower closure/drop as per Dafni et al. (2005). Further, the receptivity was also observed visually whether the stigma is shiny, wet or changing colours or withering. Twenty inflorescences other than the ones used for phenological study were tagged prior to the initiation of their flowering and followed for four weeks to record fruit and seed set rate in openpollinations. A collection of 274 pods were used to record the percentage of 1-seeded and 2-seeded pods. The fruit and seed morphological characteristics were observed in detail to evaluate their adaptations for dispersal by different means. Fields visits were made during rainy season to note the aspects of seed germination and production of new plants.

Insects foraging at the flowers were observed from morning to evening on four different days for their mode of approach, landing, probing behavior and contact with the floral sexual organs. Bees were identified with the representative specimens available with the Department of Environmental Sciences, Andhra University, Visakhapatnam. Butterflies were identified by consulting the books of Kunte (2007) and Gunathilagaraj et al. (1998). The foraging visits of insects were recorded using $1 \times 1 \mathrm{~m}$ area of flowering patch for $10 \mathrm{~min}$ at each hour for the entire day on four different days and the data was tabulated to record the foraging pattern and the percentage of visits made by bees and butterflies. The pollen/nectar collection behaviour of insects was carefully observed to assess their role in effecting pollination. Ten specimens of each insect species were captured during 0800-1100 h and brought to the laboratory. Each specimen was washed in ethyl alcohol, stained with aniline-blue on a glass slide and observed under microscope to count the number of pollen grains present. From this, the average number of pollen grains carried by each insect species was calculated to know the pollen carryover efficiency.

\section{RESULTS \\ Phenology}

The plant is a perennial prostrate herb which grows naturally in open and fallow fields and forest lands (Figure 1a). The flowering occurs throughout the year if the soil is sufficiently wet but peak flowering occured during July-September. In areas where the soil is dry during summer season, the plant withers but re-growth occurs from the perennial root stock with the commencement of rainy season in June. Seeds also germinate during rainy season and produce new plants; these plants display flowering from August onwards and continue flowering as long as the soil has enough moisture for survival and reproduction. The flowers 
were borne in axillary racemes which were covered with dense hairs; the inflorescence was crownshaped with $11.63 \pm 3.15$ flowers which opened acropetally over a time span of 4-5 days (Figure 1b).

\section{Flower morphology}

The flowers were small $(5.6 \pm 0.4 \mathrm{~mm}$ long, $6.2 \pm$ $0.7 \mathrm{~mm}$ wide), pinkish red, odourless, zygomorphic and bisexual. The calyx was green, densely hairy outside, glabrous inside, and consists of five lanceolate sepals; single sepals were $2.6 \pm 0.4 \mathrm{~mm}$ long and $1 \mathrm{~mm}$ wide. The corolla was partially gamopetalous, pinkish red and papilionaceous consisting of a broad standard petal $(4.9 \pm 0.7 \mathrm{~mm}$ long and $4.6 \pm 0.4 \mathrm{~mm}$ wide), two spathulate wing petals $(4.5 \pm 0.4 \mathrm{~mm}$ long and $2 \mathrm{~mm}$ wide) and two bottom petals $(3.6 \pm 0.4 \mathrm{~mm}$ long and $2 \mathrm{~mm}$ wide) were growing together to form the acuminate keel. All five petals were glabrous both outside and inside. The keel and the wing petals were attached by means of two notched folds. The complex of keel and wings served as a landing platform for insects visiting the flower from the front. The androecium consisted of ten creamy white 3-4 mm long glabrous stamens, diadelphous; nine filaments were fused by the basal part into a sheath open along the upper side while the tenth filament was free and lie on the others. All the ten filaments were tipped with $1 \mathrm{~mm}$ long creamy white basifixed erect anthers. The ovary ( $2 \mathrm{~mm}$ long) was green, densely hairy outside, unicarpellary, unilocular with two sessile ovules arranged on marginal placentation and lie in the sheath of the filaments along the cylindrical part of the keel (Figure 2h-j). It has a long style ( $2.5 \mathrm{~mm}$ long) with a bearded stigma (Figure 2g). The whole pistil has the same length as the stamens but the style tip with the stigma was curved upwards facing the standard petal. The entire reproductive column was housed inside the keel petals.

\section{Floral biology}

Mature buds opened during 0700-0900 h (Figure 2a). Unfolding of the standard petal and wing petals indicate flower opening (Figure 2b-d). The keel petals do not unfold but remain tensed. All the ten anthers dehisce by longitudinal slits in mature bud stage, approximately half an open prior to flower opening. The number of pollen grains per anther was $197.6 \pm 17.03$ and per flower was 1,976 \pm 170.36 . The pollen-ovule ratio was 988:1. The pollen grains were pale yellow, powdery, triangular in polar axis, isopolar, bilaterally symmetrical, exine smooth, tricolporate and $27.39 \pm 3.80 \mu \mathrm{m}$ (Figure 2f). In vitro pollen germination tests indicated that pollen grains were viable and had the ability to germinate as soon as the anthers dehisced and remain viable until $1630 \mathrm{~h}$ with a gradual decrease in germination rate (Table 1). The high pollen germination rate remains until $1230 \mathrm{~h}$ only. The stigma becomes receptive at the end of anthesis and remains so until the evening of the following day. The stigma is shiny and wet during receptive phase. A nectary is situated at the base of the flower; it is limited to the area of the receptacle. The two small fenestrae present between the joined and the free filaments facilitate access to the nectar by the foragers. The nectar was secreted in minute quantity during mature bud stage and it was concealed by the hook-like structures of the standard petal which hold the basal part of the wing and keel petals intact. It was present in traces in flowers due to feeding by thrips in buds. Thrips use the growing buds for breeding and emerge by the time the buds bloom. During mature bud, anthesis and post-anthesis, the thrips continually feed on nectar and pollen. The petals and stamens fall off on the third day in pollinated flowers while the entire flower falls off in un-pollinated flowers.

\section{Pollination mechanism}

The staminal column and pistil are held under pressure within the pouch-like keel petals, and when the pressure is released, the staminal column and stigma snap forward against the standard petal causing the pollen to be instantly released (Fig. 2e). This process constitutes tripping mechanism and it is accomplished when the keel petals are pressed down by a foraging insect. High wind speed, heavy rain and high temperature that weaken the turgidity of the restraining keel tissues can cause tripping of the keel petals which spontaneously release the staminal column and stigma. If the flowers are untouched, the stamens and pistil remain within the keel and subsequently fall off without pollination. Insects landing on the front of the flower, especially on the wing petals, ride the keel petals with their legs by pushing down the wing petals which in turn pull back the keel petals by the notched folds. Once tripping occurs, the staminal column and the pistil do not return into the keel petals and so are the keel petals. Such a wing-keel complex tripping mechanism characterizes explosive pollination mechanism. Since the stigma stands above the anthers, the foraging insect during probing first brushes against the stigma followed by the anthers with its ventral side. If the insect carries pollen on its ventral side from the flowers which it visited previously, then cross-pollination occurs or else 
self-pollination occurs. In case of abiotic factors, wind, rain and temperature tripping the keel complex, only self-pollination occurs. The explosive pollination mechanism functional in this plant is adapted for manipulation by both biotic and abiotic factors.

Table 1. In vitro pollen germination in Indigofera linnaei.

\begin{tabular}{ccc}
\hline Time (h) & Pollen sample & Germination (\%) \\
0830 & 100 & 88 \\
0930 & 100 & 47 \\
1030 & 100 & 21 \\
1130 & 100 & 18 \\
1230 & 100 & 12 \\
1330 & 100 & 7 \\
1430 & 100 & 4 \\
1530 & 100 & 2 \\
1630 & 100 & 1 \\
1730 & 100 & 0 \\
\hline
\end{tabular}

Pollen germination was recorded in $15 \%$ pure sucrose solution.

\section{Insect visitors and pollination}

Thrips were the first and resident foragers. They were ineffective in tripping the keel petals but were found to be contributing to primarily selfpollination by feeding on both pollen and nectar during mature bud and during and after anthesis. The flowers were foraged by bees and lycaenid butterflies (Table 2). The bees were Apis florea and Ceratina sp. Lycaenid butterflies were Zizeeria karsandra (Figure 3a), Zizina otis (Figure 3b); Freyeria trochylus (Figure 3c); Chilades laius (Figure 3d) and Chilades pandava (Figure 3e). Foraging was observed during daytime from 0800 to $1300 \mathrm{~h}$ with concentrated foraging activity during 0900-1100 h (Figure 4). Bees made 33\% and lycaenids $67 \%$ of total foraging visits (Figure 5). The bees always approached the flower from the front with the head facing the standard petal while the lycaenids approached the flower also from the top of the standard petal with the head facing the wing-keel complex. The bees inserted the glossa under the standard petal to reach the nectar while the butterflies inserted the proboscis gently through the gap between the standard petal and the wingkeel complex for nectar collection. In this probing behavior, the keel petals were tripped, stigma brushed and pollen ejected violently against the ventral side of thorax and abdomen of the insects and this ended up in cross and/or self-pollination. When the butterflies approached from the top of the standard petal, they slowly inserted the proboscis into the flower base for nectar collection during which keel petals were tripped, stigma brushed and pollen ejected violently against the head and the adjacent parts, this also ended up in cross and/or self-pollination. The bees turned around towards the staminal column to collect pollen from the anthers and sometimes they also collected pollen that was deposited on the inside of the standard petal. They did not discriminate between the stigma and anthers while probing for pollen collection and in effect, they invariably gathered pollen also from the stigma. In most of the foraging visits, the bees probed for nectar and pollen while in other visits, they collected either nectar or pollen. Comparatively, bees were more effective in tripping the flowers and effecting pollination. The small and delicate flowers equipped with explosive pollination mechanism were found to be facilitating the lycaenid butterflies to trip the keel petals. These insects visited 5-6 flowers consecutively and in some cases many more up to 21-25 before leaving the flowering patch. The insects were not disturbed during probing by the tripping of keel petals and made consistent foraging visits as long as the flower density was prominent at plant level. As the flowers were depleted of nectar by thrips, the insects made multiple visits to the same flowers in quest of nectar and/or pollen. The pollen carrying efficiency evaluated by body washings of captured insects indicated that honey bees were more 
efficient in carrying pollen than butterflies; the average number of pollen grains recorded varied from 43.1 to 30.2 for honey bees and small carpenter bees and from 22.1 to 17.1 for butterflies (Table 3). The insects foraged the flowers in quick succession from one inflorescence to the other on the same and/or different plant populations in order to collect as much pollen and/or nectar as possible; this inter-inflorescence/plant foraging activity was considered to be promoting cross-pollination.

Table 2. List of insect foragers on Indigofera linnaei.

\begin{tabular}{llllll}
\hline Order & Family & Genus & Species & Common name & Forage sought \\
\hline Hymenoptera & Apidae & Apis & florea F. & Dwarf Honey Bee & Pollen + Nectar \\
& & Ceratina & sp. & Small Carpenter Bee & Pollen + Nectar \\
Lepidoptera & Lycaenidae & Zizeeria & karsandra Moore & Dark Grass Blue & Nectar \\
& & Zizina & otis F. & Lesser Grass Blue & Nectar \\
& & Freyeria & trochylus Freyer & Grass Jewel & Nectar \\
& & Chilades & laius Stoll & Lime Blue & Nectar \\
& & Chilades & pandava Horsfield & Plains Cupid & Nectar \\
\hline
\end{tabular}

Table 3. Pollen recorded in the body washings of bee and lycaenid butterfly foragers on Indigofera linnaei.

\begin{tabular}{lllcl}
\hline Insect species & Sample size & \multicolumn{3}{c}{ Number of pollen grains } \\
\cline { 3 - 5 } & $\mathbf{( N )}$ & Range & Mean & S.D \\
\hline Apis florea & 10 & $18-67$ & 43.1 & 14.34 \\
Ceratina sp. & 10 & $20-43$ & 30.2 & 6.11 \\
Zizeeria karsandra & 10 & $9-24$ & 20.9 & 5.73 \\
Zizina otis & 10 & $11-28$ & 18.2 & 5.9 \\
Freyeria trochylus & 10 & $8-25$ & 19.1 & 4.25 \\
Chilades laius & 10 & $12-31$ & 22.1 & 6.20 \\
Chilades pandava & 10 & $10-29$ & 17.1 & 5.59 \\
\hline
\end{tabular}

\section{Fruiting ecology}

The pollinated and fertilized flowers grew continually and produce pods (fruits) in three weeks. An inflorescence produced $8.46 \pm 2.88$ pods. Natural fruit set rate was $91.33 \%$ and seed set rate $81.16 \%$. The pods were green initially and brown when mature (Figure $2 \mathrm{k}$ ); they were sessile, non-fleshy, cylindrical, falcate, hairy, $4.3 \pm 0.5 \mathrm{~mm}$ long and $2 \mathrm{~mm}$ wide; they produced one or two seeds. 1-seeded pod set rate at was $23 \%$ while 2seeded pod set rate was $77 \%$. The seeds were irregularly shaped, oily, light brown, glabrous, lustrous, $2 \mathrm{~mm}$ long and $2 \mathrm{~mm}$ wide (Figure $2 \mathrm{~m}$ ). The pods dispersed seeds by explosive dehiscence (Figure 21). The dispersed seeds fall to the ground quickly due to low height of the mother plant. Subsequently, the seeds disperse through wind during summer season and rain water during rainy season. The seeds were dormant and germinated only during rainy season which starts in June. They did not germinate in the lab conditions. Erratic rainfall and long dry spells during rainy season terminated the growth and development of seedlings. The old plants with their robust underground root system withstood fluctuations in rainfall levels and continued their phenological events sequentially. However, the aerial plants withered away during extreme dry soil conditions, the situations of which occur during dry season only. 

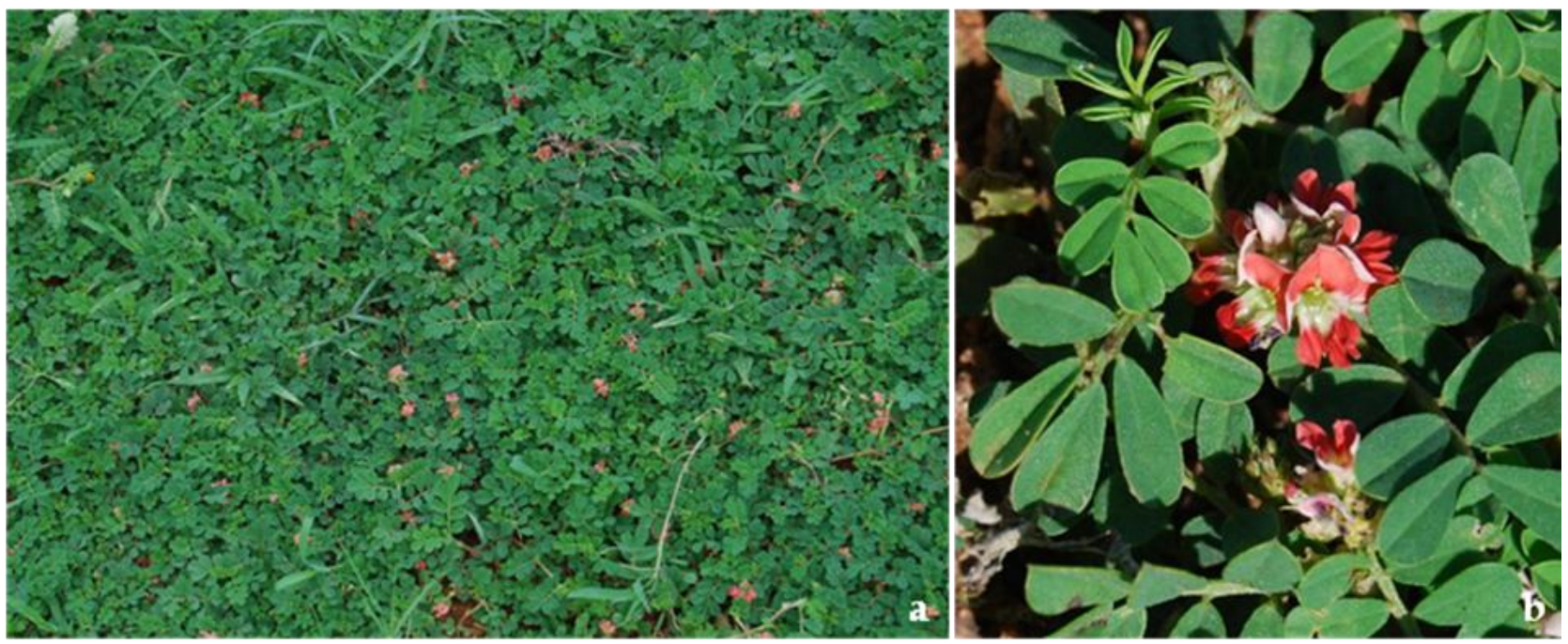

Figure 1. Indigofera linnaei: a. Habit, b. Flowering inflorescence.
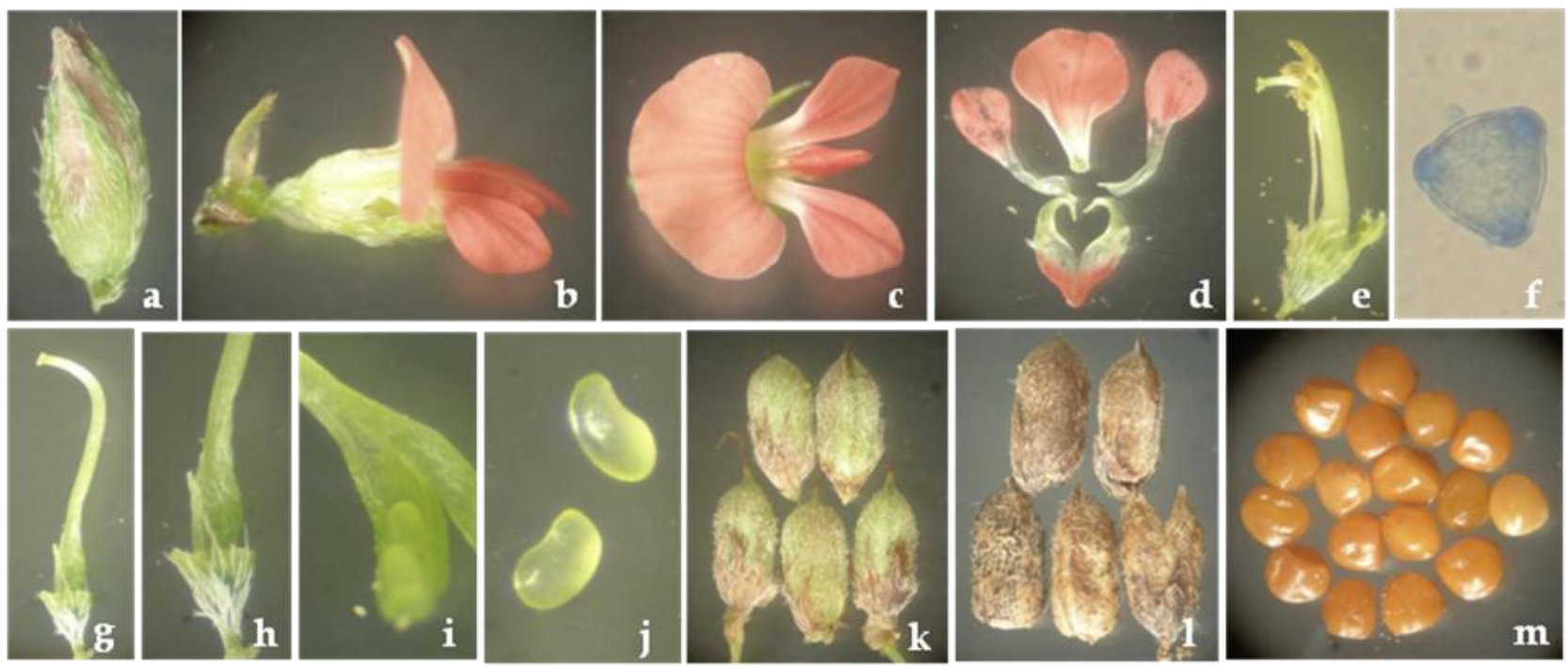

Figure 2. Indigofera linnaei: a. Mature bud, b. Flower, c. \& d. Papilionaceous corolla, e. Position of sex organs, f. Pollen grain, g. Ovary with style and stigma, h. \& i. 2-ovuled ovary, j. Ovules, k. Mature pods, I. Dry pods, m. Seeds.
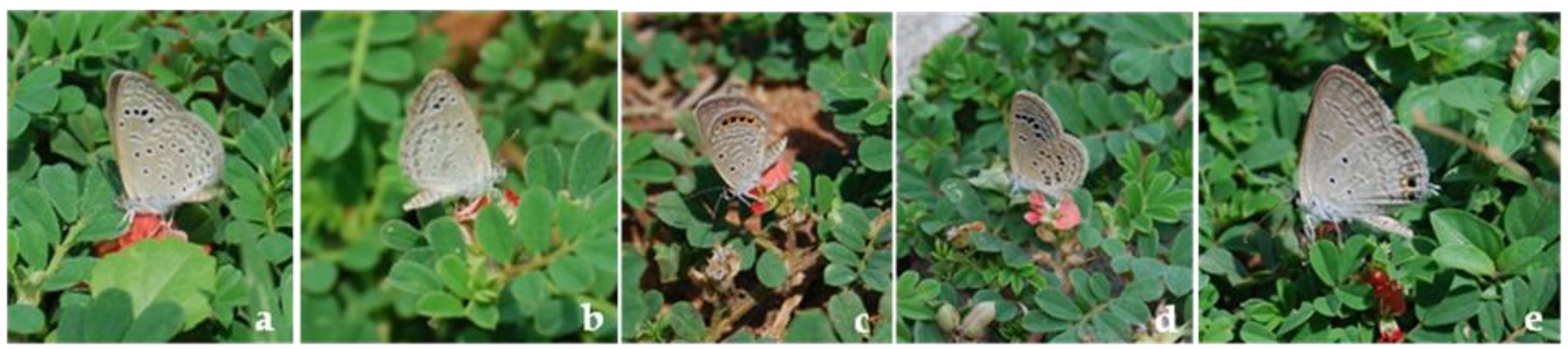

Figure 3. Indigofera linnaei: Lycaenid butterflies - a. Zizeeria karsandra, b. Zizina otis, c. Freyeria trochylus, d. Chilades laius, e. Chilades pandava. 


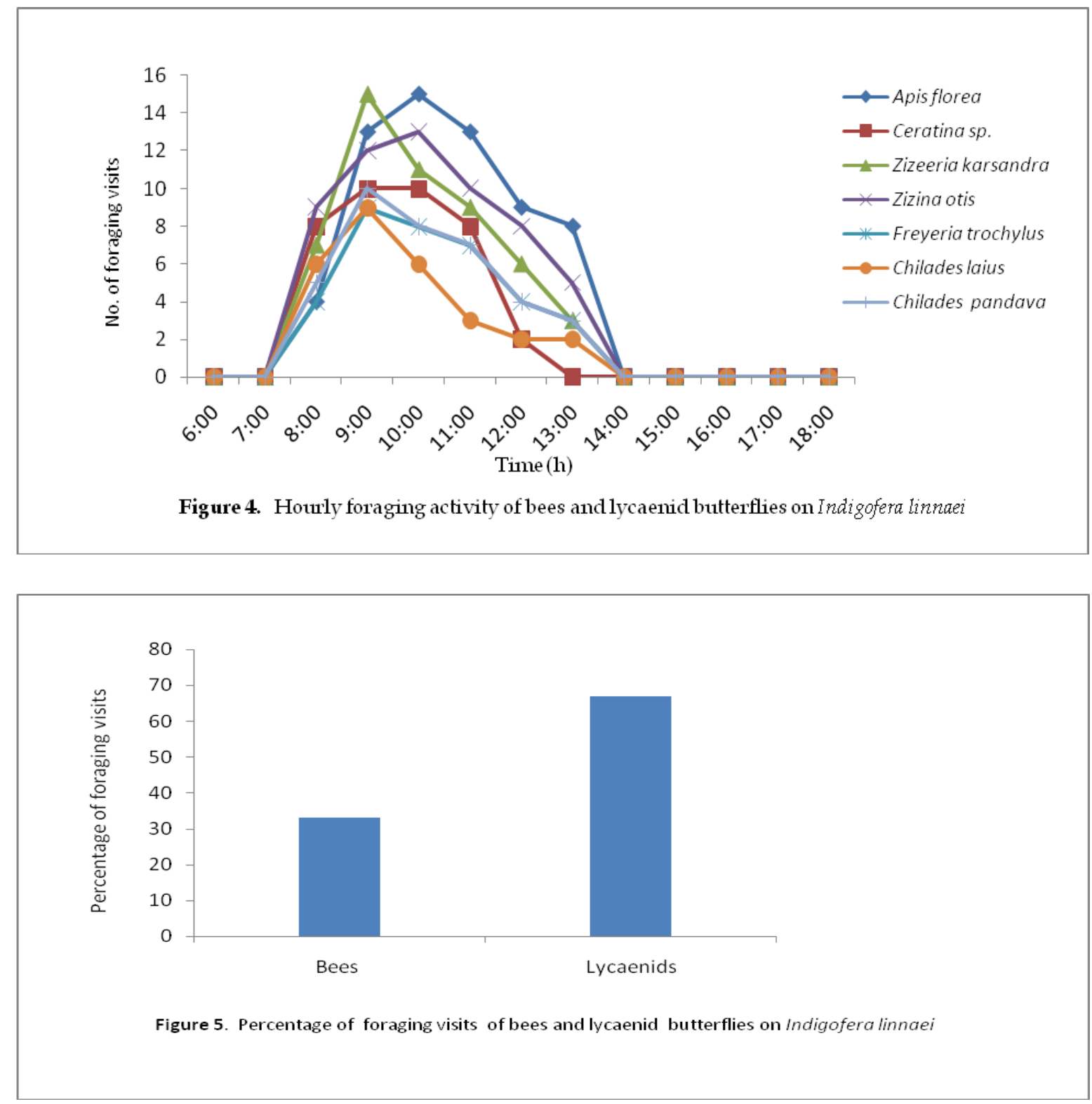

\section{DISCUSSION}

Indigofera linnaei grows throughout the year and displays profuse to sporadic flowering and intense fruiting if the soil is sufficiently wet and nutrientrich. The plant disappears if the soil is dry but the woody root stock stays below ground. The plant appears again from this rooting system during rainy season. Seed production is continuous in plants growing in areas of moist soils; but seeds are dormant and germinate only during rainy season to produce new plants and populations. The plant with dual modes of regeneration exhibits prolific growth during rainy season. Individual plants grow side by side, form pure populations and closely cover the soil. The flowers are pinkish red, borne in leaf axils and stand out above the foliage; such a pattern of flower production gives the view that the entire green foliage mat at ground level is decorated with the flowers. The occurrence of the plant can be recognized easily from a long distance, especially during its peak flowering season which is confined to July-September.

In I. linnaei, the papilionaceous corolla conceals the stamens and stigma concealed in the keel petals even after anthesis. The keel petals require tripping to expose the sex organs. The abiotic and biotic agents trip the keel petals due to which the sex organs are exposed. The abiotic agents, high winds, heavy rain and high temperature weaken the turgidity of the restraining keel tissues and in effect the tripping occurs causing the spontaneous release of the sex organs. In this act, the tripping facilitates autogamy but to what extent this mode of pollination occurs is situational depending on the 
force exerted on the keel petals and the prevailing ambient environment. Bees and lycaenid butterflies also cause the tripping of keel petals causing the sudden release of the sex organs. This tripping of keel petals facilitates autogamy but it is not definite; these insects also affect geitonogamy and xenogamy depending on the pollen carried by them on their ventral side. The high natural fruit set and seed set rates recorded in this study suggest that the plant has mixed breeding system consisting of autogamy, geitonogamy and xenogamy. But, it is principally facultative autogamous due to the function of autogamy both by abiotic and biotic agents. Further, the floral characteristics such as a low investment in attractive structures, such as petals, nectar and pollen, short period of anthesis schedule, self-compatibility and low pollen/ovule ratio confirm that $I$. linnaei is facultative autogamous (Faegri \& van der Pijl, 1979; Cruden \& Miller-Ward, 1981). The long period of stigma receptivity is certainly an evolved character to achieve geitonogamy and xenogamy in the late evening of the day of anthesis and also on the following day since self-pollen within the flowers is not viable after $1630 \mathrm{~h}$ on the day of anthesis. Insect activity also brings about geitonogamy and xenogamy in day 1 and day 2 flowers by tripping the keel petals. Autogamy does not occur in day 2 flowers by abiotic and biotic agents due to in-viable self-pollen and only geitonogamy and xenogamy can occur in such flowers due to the function of abiotic and biotic agents. The production of numerous seedlings in the vicinity and adjacent areas of the parental populations during rainy season suggest that seeds produced from self- as well as cross-pollinations are viable. Therefore, the mixed breeding system is a "fail-safe system" to assure I. linnaei to have high seed set rate and eventually to qualify itself as a colonizer species.

In the present study, I. linnaei flowers exhibit functional explosive pollination mechanism. In this mechanism, the keel petals with the staminal column together with the pistil is held under tension, and following tension release by the tripping caused by either abiotic or biotic agents, the sex organs snap forward against the standard petal causing all the pollen to be instantly ejected. In this process, autogamy can occur but the probability of its occurrence is situational depending on the ambient environment and the force with which the tripping of keel petals is caused. In the tripped flowers, either the keel petals or the staminal column and stigma do not return to their original positions. The flowers with this explosive pollination mechanism are specialized for tripping by external agents. Further, the concealment of the stamens within the keel until it is tripped is an adaptation to secure pollen from rainfall, and such an adaptation is essentially required for I. linnaei which is a low ground prostrate herb and is prone to rain water flooding. The containment of the stamens and also stigma within the keel after anthesis appears to be a mechanism evolved to protect the pollen from moisture during low ambient temperature and dew at night and also to maintain pollen fertility because its fertility will be affected through contact with water on rainy days and cool humid days; this protection is very much required for the flowers which were not tripped on the day of anthesis (Peter et al., 2004).

Small (1988) stated that Medicago species of the tribe Trifolieae with explosive pollination mechanism displays the lowest pollen-ovule ratios. Lopez et al. (1999) recorded explosive pollination mechanism with highest pollen-ovule ratios in certain genera of the Fabaceae such as Cytisus, Pterospartum, Teline, Ulex, Stauracanthus and Cytisophyllum. Etcheverry et al. (2012) noted that the Fabaceae plants which they studied with explosive pollination mechanism had intermediate pollen-ovule ratios. Padmavathi et al. (2012) reported that Indigofera barberi with explosive pollination mechanism had intermediate pollenovule ratio. In the present study, I. linnaei with explosive pollination mechanism has low pollenovule ratio; it is almost half of the pollen-ovule ratio recorded for I. barberi. Therefore, the study suggests that I. linnaei is facultative autogamous and accordingly its pollen-ovule ratio is in conformity with the pollen-ovule ratio used by Cruden (1977) for the same breeding system.

The plants with explosive pollination mechanism depend on pollen vectors because they cannot selfactivate the tripping process to affect autogamy. It is more so in Fabaceae members that present four types of pollination mechanisms (Aronne et al., 2012). In Fabaceae, the papilionaceous corolla is considered to be a general adaptation to pollination by Hymenoptera. Subsequent sternotribic pollination events can occur within a single flower (Faegri \& van der Pijl, 1979). Therefore, all pollen produced within a flower can be potentially delivered to those insects which are able to trigger the mechanism without any waste suggesting that the pollen is placed in such positions on the insects' 
bodies that it is difficult for them to brush it off (Westerkamp, 1997). In the present study, I. linnaei with explosive pollination mechanism attracts only certain bees and lycaenid butterflies despite the occurrence of different categories of hymenopterans including various bees, wasps, butterflies and moths in the habitat of the plant. The principle reason could be that the flowers are small, odourless, pinkish red. In this context, it is appropriate to state the observation of Hingston \& McQuillan (2000) that Indigofera species with purple zygomorphic flowers are not attractive to bees compared to the yellow flowers of other Fabaceae members. These authors also specifically noted such a situation in case of $I$. australis in Tasmania. The present study indicated that lycaenid butterflies are less efficient compared to bees in tripping the explosive pollination mechanism; however, both categories of insects are involved in tripping the mechanism due to very delicate corolla. But, bees are the appropriate pollinators which while collecting nectar and pollen effect self- and cross-pollination. The bees and butterflies do not forage throughout the day and cease their foraging activity by noon time despite the occurrence of flowers. Such a foraging schedule indicates that most of the standing crop of floral rewards gets exhausted by then and thereafter the visits of insects to the flowers are not energetically profitable since there is less reward to be removed. The availability of traces of nectar in the flowers due to feeding of pollen and nectar by thrips appears to be advantageous for the plant to increase foraging visits across conspecific populations and promote outcrossing. Marina Fernanda et al. (2008) reported that Indigofera species pollen contain oil, starch grains and protein bodies. In I. linnaei also, the pollen is oily and it could be a potential nutrient source for bees. In un-tripped flowers, the staminal column and the pistil remain within the keel and subsequently fall off without pollination. Therefore, I. linnaei with explosive pollination mechanism adapted for pollination by abiotic and biotic agents is able to produce highest natural fruit and seed set rates through autogamy, geitonogamy and xenogamy.

In I. linnaei, seed dormancy is another important character of the plant that facilitates germination only during rainy season during which the soil absorbs and stores sufficient moisture. This dormancy enables the plant to save the seed source and use the same for the colonization of the areas during rainy season. In recent years, rainfall is insufficient and also long dry spells exist within rainy season. In consequence, the seedlings struggle to survive and if there is not enough soil moisture, they do not show any further growth and subsequently perish. However, the re-growth from the well established old root stock withstands rain deficit and produces new plants alleviating the loss of seedlings from the seeds to some extent. Therefore, the seed dormancy and the production of new plants from the old root stock enable the plant to occupy various habitats to extend and expand its distribution range. In this context, it is appropriate to mention that explosive pod dehiscence facilitates seed dispersal to different distances on the ground and the seeds with irregular shape and oily nature subsequently disperse through wind and rain water. Therefore, I. linnaei shows ballistichory, anemochory and hydrochory; these modes of seed dispersal benefit the plant to invade and colonize new areas.

Indigofera linnaei is used for promoting hair growth, chronic bronchitis, asthma, ulcers, skin diseases, in gastropathy and in epilepsy (Kumanan et al., 2014). Since the plant is used in traditional medicine, it can be scientifically used in the modern forms of medicine while allowing it to grow in areas where it is not a menace from the human point of view.

\section{REFERENCES}

Aronne, G.; Giovanetti, M. and De Micco, V. (2012). Morphofunctional traits and pollination mechanisms of Coronilla emerus L. flowers (Fabaceae). The Sci. World J. Article ID 381575, pp. 8.

Collevatti, R. G.; Campos, L. A. O. and Da Silva, A. F. (1998). Pollination ecology of the tropical weed Triumfetta semitriloba Jacq. (Tiliaceae), in the south-eastern Brazil. Revista Brasileira de Biologia, 58: 383-392.

Cruden, R. W. (1977). Pollen-ovule ratios: a conservative indicator of breeding systems in flowering plants. Evolution, 31: 32-46.

Cruden, R. W. and Miller-Ward, S. (1981). Pollenovule ratios, pollen-size, and the ratio of stigmatic area to the pollen-bearing area of the pollinator: a hypothesis. Evolution, 35: 964-974.

Dafni, A.; Kevan, P. G. and Husband, B. C. (2005). Practical Pollination Biology. Enviroquest, Ltd., Cambridge, pp. 590. 
Dowarah, J.; Boruah, H. P. D.; Gogoi, J.; Pathak, N.; Saikia, N. and Handique, A. K. (2009). Eco-restoration of a high-sulphur coal mine overburden dumping site in northeast India: a case study. Journal of Earth System Science, 118: 597-608.

Etcheverry, A. V.; Aleman, M. M.; FigueroaFleming, T.; Lopez-Spahr, D.; Gomez, C. A.; Yanez, C. et al. (2012). Pollen: ovule ratio and its relationship with other floral traits in Papilionoideae (Leguminosae): an evaluation with Argentine species. Plant Biology (Stuttg), 14: 171-178.

Faegri, K. and van der Pijl, L. (1979). The Principles of Pollination Ecology. Pergamon Press, Oxford, UK. pp. 256.

Gebrekirstos, A.; Teketay, D.; Fetene, M. and Mitlohner, R. (2006). Adaptation of five cooccurring tree and shrub species to water stress and its implication in restoration of degraded lands. Forest Ecology and Management, 229: 259-267.

Gunathilagaraj, K.; Perumal, T. N. A.; Jayaram, K. and Ganesh Kumar, M. (1998). Field Guide: Some South Indian Butterflies. Niligiri Wildlife and Environmental Association, Niligiri. pp. 274.

Hingston, A. B. and McQuillan, P. B. (2000). Are pollination syndromes useful predictors of floral visitors in Tasmania? Austral Ecology, 26: 600-609.

Kumanan, R.; Sridhar, C.; Jayaveera, K. N. and Sudh, S. (2014). Comparative study of Stylosanthes fruticosa and Indigofera linnae for anthelmintic activity. Indian Journal of Research in Pharmacy and Biotechnology, 2: 1237-1239.

Kumar, R.; Ambasht, R. S.; Srivastava, A.; Srivastava, N. K. and Sinha, A. (1997). Reduction of nitrogen losses through erosion by Leonotis nepetaefolia and Sida acuta in simulated rain intensities. Ecological Engineering, 8: 233-239.

Kunte, K. (2007). A lifescape of butterflies of peninsular India. University Press, Hyderabad. pp. 254.
Lopez, J.; Rodriguez-Riano, T.; Ortega-Olivencia, A.; Devesa, J. A. and Ruiz, T. (1999). Pollination mechanisms and pollen-ovule ratios in some Genisteae (Fabaceae) from Southwestern Europe. Plant Systematics \& Evolution, 216: 23-47.

Marina Fernanda, B. C.; Juliana Villela, P. and Teixeira, S. P. (2008). XX International Congress on Sexual Plant Reproduction, Brasilia, Brazil, pp. 137-138.

Okuyama, T. and Holland, J. N. (2008). Network structural properties mediate the stability of mutualistic communities. Ecological Letters, 11: 208-216.

Padmavathi, P. L.; David, K. M.; Rao, M. S. and Rama Gopal, G. (2012). Studies on the flowering phenology and pollen biology of Indigofera barberi Gamble, an endemic plant of Tirumala hills. Current Biotica, 5: 405-412.

Peter, C. I.; Dold, A. P.; Barker, N. P. and Ripley, B. S. (2004). Pollination biology of Bergeranthus multiceps (Aizoaceae) with preliminary observations of repeated flower opening and closure. South African Journal of Science, 100: 624-628.

Small, E. (1988). Pollen-ovule patterns in the tribe Trifoliae (Leguminosae). Plant Systematics \& Evolution, 160: 195-205.

Westerkamp, C. (1997). Flowers and bees are competitors not partners. Towards a new understanding of complexity in specialized bee flowers. In: Pollination: from theory to practice. K.W. Richards (ed) Proceeding of 7th International Symposium on Pollination. Acta Horticulturae, 437: 71-74.

Wilson, P. G. (1987). Taxonomic notes on some Australian species of Indigofera (Fabaceae): Faboideae). Journal of Adelaide Botanic Gardens, 10: 119-126.

Wilson, P. G. and Ross, R. (2004). A revision of the Indigofereae (Fabaceae) in Australia. 1. Indigastrum and the simple or unifoliolate species of Indigofera. Telopea, 10: 651-682. 